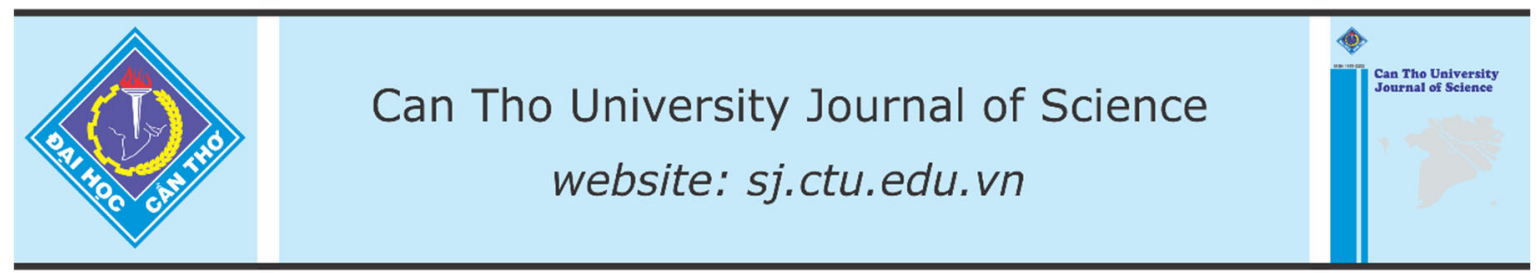

DOI: $10.22144 /$ ctu.jen.2019.009

\title{
Comparative study of preparation and characterization of palladium nanosheets
}

Tran Thi Bich Quyen ${ }^{1 *}$, Nguyen Thi Xuan $\mathrm{Chi}^{1}$, Nguyen Thi Diem Nhi ${ }^{1}$, Doan Van Hong Thien ${ }^{1}$, Luong Huynh Vu Thanh ${ }^{1}$ and Bui Le Anh Tuan ${ }^{2}$

${ }^{1}$ Department of Chemical Engineering, College of Technology, Can Tho University, Vietnam

${ }^{2}$ Department of Civil Engineering, Can Tho University, Vietnam

${ }^{*}$ Correspondence: Tran Thi Bich Quyen (email: ttbquyen@ctu.edu.vn)

\section{Article info.}

Received 12 Jan 2018

Revised 26 Mar 2018

Accepted 29 Mar 2019

\section{Keywords}

Catalytic, characterization, CO gas, palladium nanosheets (Pd NSs), plasmonic, tungsten hexacarbonyl $\left(\mathrm{W}(\mathrm{CO})_{6}\right)$

\begin{abstract}
A simple and effective approach has been developed to synthesize palladium nanosheets that were successfully employed by reducing the Pd salt precursor in $N, N$-dimethylformamide (DMF), cetyltrimethylammonium bromide (CTAB), citric acid and using various reducing agents of CO gas and tungsten hexacarbonyl $\left(\mathrm{W}(\mathrm{CO})_{6}\right)_{\text {. I }}$. indicates to be a novel method for the synthesis, providing a cost effective and an efficient route for the Pd nanosheets' synthesis. The prepared Pd nanosheets have been characterized by ultraviolet-visible spectroscopy (UV-vis), transmission electron microscope (TEM) and $X$-ray diffraction $(X R D)$. The results showed those $P d$ nanosheets have been obtained with the average edge length of $\sim 20-25$ $\mathrm{nm}$ (using $\mathrm{CO}$ gas) and around $\sim 20 \mathrm{~nm}$ (using $W(\mathrm{CO})_{6}$ ). Thus, the method using $W(C O)_{6}$ as a reducing agent could be an alternative the route to use $C O$ gas for the synthesis of Pd nanosheets. Since, the synthesized Pd nanosheets with highly plasmonic and catalytic properties are potential materials for applications in photothermal therapy, biosensor, catalyst and so on in the current and in future.
\end{abstract}

Cited as: Quyen, T.T.B., Xuan Chi, N.T.X., Nhi, N.T.D., Thien, D.V.H., Thanh, L.H.V. and Tuan, B.L.A., 2019. Comparative study of preparation and characterization of palladium nanosheets. Can Tho University Journal of Science. 11(1): 64-69.

\section{INTRODUCTION}

For years, nanomaterials have shown substantially distinctive properties as compared to bulk materials (Rao, 2004; Huang et al., 2013). Properties such as magnetic, optical, electronic, catalytic and electrocatalytic activities could significantly depend on the size and shape of the metal nanoparticles (Sun, 2000). Thus, ultrathin noble metal nanosheets have recently attracted considerable attentions because of their high surface area-to-volume ratio and high density unsaturated atoms exposed on the surface, which can significantly enhance their plasmonic properties and catalytic activities (Huang et al., 2010, 2011; Perez-Alonso et al., 2012; Saleem et al., 2013; Duan et al., 2014; Yin et al., 2014; Hong et al., 2016).

Palladium (Pd) is a key component of many catalysts applied in industrial processes and commercial devices (Roucoux et al., 2002). Therefore, $\mathrm{Pd}$ is a flexible catalyst for a large number of importantly industrial reactions such as a number of important C-C coupling reactions and hydrogenation of unsaturated organic compounds (Franzén, 2000; Li et al., 2000; Reetz et al., 2000; Son et al., 2004; Redjala, 2006; Astruc, 2007; Berhault et al., 2007). In addition, Pd nanoparticle is also a using material for sensing and hydrogen 
storage (Tobiška, 2001; Hübert et al., 2011). For example, Pd nanowire arrays were found to be very active catalysts for ethanol oxidation for direct alcohol fuel cells (Xu et al., 2007). Thus, controlling the shape of Pd nanostructures is important not only in enhancing the catalytic activity but also for other applications such as surface-enhanced Raman scattering (SERS), optical sensing and hydrogen storage for plasmonic sensing (Xiong et al., 2005; Li et al., 2006; Langhammer, 2007). Besides, twodimensional Pd nanoparticles show ferromagnetic properties that differ from those of bulk $\mathrm{Pd}$, which has been reported previously (Bouarab et al., 1990; Mendoza, 1999; Suzuki, 2000). Moreover, recent studies also demonstrated that the Pd nanoplates have greater capacity for hydrogen absorption and localized surface plasmon resonance (LSPR) peaks absorption in the near-infrared region (NIR) for biological applications than bulk Pd and spherical Pd nanoparticles (Kishore et al., 2005; Xiong, 2005; Xiong et al., 2005 ). In this work, a simple approach to synthesize the Pd nanosheets was successful developed using citric acid, cetyltrimethylammonium bromide (CTAB), N,Ndimethylformamide (DMF) and tungsten hexacarbonyl $\left(\mathrm{W}(\mathrm{CO})_{6}\right)$ as reducing agents for $\mathrm{Pd}$ precursor $\left(\mathrm{Pd}(\mathrm{acac})_{2}\right)$. Herein, the Pd nanosheets' synthetic method used here is simple, cost effective, performable (easy to be done), uniform in particle size, stable and sustainable. Since, it shows that the synthesized Pd nanosheets is a promising material for applications in the field of catalysis and plasmonic (i.e. fuel cells, and sensing, etc.) in the recent time and in future.

\section{MATERIALS AND METHODS}

\subsection{Materials}

Palladium (II) acetylacetonate (Pd(acac) $\left.)_{2}, 99 \%\right)$; polyvinylpyrrolidone (PVP; $\quad \mathrm{M}_{\mathrm{wt}} \sim 10.000$ ); tungsten hexacarbonyl $\left(\mathrm{W}(\mathrm{CO})_{6} ; 97 \%\right)$ and $\mathrm{N}, \mathrm{N}-$ Dimethylformamide (DMF) were purchased from Sigma-Aldrich and Merck. CTAB, acetone, ethanol, and citric acid were bought from Acros. $\mathrm{CO}$ gas was purchased from gas company in Vietnam. All solutions were prepared using deionized water from a MilliQ system.

\subsection{Methods}

\subsubsection{Synthesis of Pd nanosheets}

Palladium nanosheets (Pd NSs) were synthesized by a novel and simple method using tungsten hexacarbonyl as a reducing agent without using $\mathrm{CO}$ gas directly. In a typical synthesis, $60 \mathrm{mg}$ of CTAB and $30 \mathrm{mg}$ of PVP were dissolved in $10 \mathrm{~mL}$ of DMF. And then, $16 \mathrm{mg}$ of $\mathrm{Pd}(\mathrm{acac})_{2}$ and citric acid $(10 \mathrm{mg})$ were also added to $10 \mathrm{~mL}$ of the above DMF mixture and stirred for $20 \mathrm{~min}$ at room temperature. The homogeneous solution above was transferred into a $50 \mathrm{~mL}$ glass (flask), and $100 \mathrm{mg}$ of $\mathrm{W}(\mathrm{CO})_{6}$ was quickly added into the flask or using $\mathrm{CO}$ gas directly as a reducing agent for the reduction of $\operatorname{Pd}(\mathrm{acac})_{2}$ in 30 seconds. After that, the solution was continuously stirred and heated at $80^{\circ} \mathrm{C}$ for various reaction times of $60 \mathrm{~min}$; $75 \mathrm{~min} ; 90 \mathrm{~min}$; and 120 min, respectively. Upon temperature and time of reaction, the reaction mixture went through a series of color changes that included dark, light blue, and dark blue, etc. The solution was then centrifuged $(10,000 \mathrm{rpm} ; 15 \mathrm{~min})$, washed with acetone to remove excess and redispersed in ethanol. The average edge lengths of the as-prepared $\mathrm{Pd}$ nanosheets are $\sim 15-20 \mathrm{~nm}$ (using $\mathrm{W}(\mathrm{CO})_{6}$ as a reducing agent) and $\sim 20-25 \mathrm{~nm}$ (using $\mathrm{CO}$ gas directly as a reducing agent) for comparison, respectively.

\subsubsection{Characterization}

The absorbance spectra of Pd nanosheet solutions were examined by UV-vis spectrophotometry (UV675; Shimadzu). The phase structure of $\mathrm{Pd}$ nanosheet was determined by an X-ray diffractometer (Rigaku Dmax-B, Japan) with $\mathrm{Cu}$ $\mathrm{K}_{\alpha}$ source operated at $40 \mathrm{kV}$ and $100 \mathrm{~mA}$. A scan rate of $0.05 \mathrm{deg}^{-1}$ was used for $2 \theta$ between $10^{\circ}$ and $80^{\circ}$. The shape and particle size of Pd nanosheets were examined by transmission electron microscope (TEM) with a Philips Tecnai F20 G2 FEI-TEM microscope (accelerating voltage $200 \mathrm{kV}$ ).

\section{RESULTS AND DISCUSSIONS}

As shown in Figure 1, the UV-vis spectra of Pd nanosheets (Pd NSs) exhibited with the maximum absorption peak in the NIR region from $835 \mathrm{~nm}$ to $1050 \mathrm{~nm}$ (Figure 1A) and from $718 \mathrm{~nm}$ to $932 \mathrm{~nm}$ (Figure 1B), respectively. Herein, the plasmon resonance peaks match with the surface absorption of Pd nanosheets (Kooij, 2011). Since, it is demonstrated that Pd nanosheets are created in the synthesized solution. When the reaction time of the $\mathrm{Pd}$ nanosheets mixture solution is increased, leading to the maximum absorption peaks also gradually shifted respective from 835 to $1050 \mathrm{~nm}$ and from 718 to $932 \mathrm{~nm}$ (from visible to the NIR region) due to the enhanced aspect ratio for the two-dimensional anisotropy (Li et al., 2015), respectively (Figure 1). However, the reaction time is increased, leading to the intensity of absorption peaks decreased gradually (Figure 1(A) (b, c) and 1(B) (c, d), respectively). This may be due to the solution occurs the agglomeration of nanoparticles together, resulting in the solution's color decreases gradually. 
Therefore, the optimal sample with reaction time at $90 \mathrm{~min}$ is chosen to investigate other factors in the steps following. Moreover, the synthesized $\mathrm{Pd}$ nanosheets with reaction time at 90 min using $\mathrm{CO}$ gas directly as a reducing agent obtained the maximum absorption peak $\sim 945 \mathrm{~nm}$ (Figure 1(A) (b)) were larger than that of Pd nanosheets using $\mathrm{W}(\mathrm{CO})_{6}$ as a reducing agent with the absorption peak around $932 \mathrm{~nm}$ (Figure 1(B) (c)) for comparison (Figure 1). Since, the particle size of $\mathrm{Pd}$ nanosheets using $\mathrm{CO}$ gas directly be predicted was larger as compared to that of Pd nanosheets using $\mathrm{W}(\mathrm{CO})_{6}$ as a reducing agent.

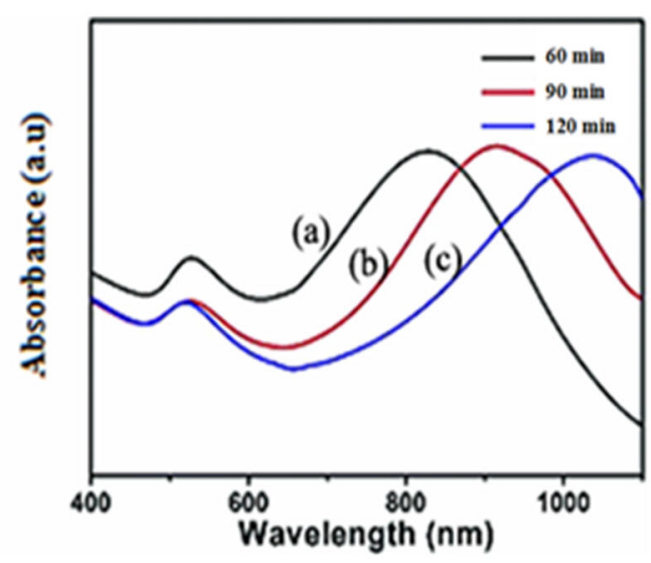

The presence of free ions in the CTAB, citric acid and $\mathrm{W}(\mathrm{CO})_{6}$ or $\mathrm{CO}$ gas has greatly accelerated for the polyol synthesis of ultrathin $\mathrm{Pd}$ nanosheets. During the synthesis, the nanoparticles production could easily monitor the progress through its color changes from black to light blue or dark blue, etc. due to a dramatic increase in the reduction rate of $\mathrm{Pd}$ ions $\left(\mathrm{Pd}^{2+}\right)$ to form the $\mathrm{Pd}$ nanosheet. The absorptive intensity of synthesized samples tends to proportional increase to the $\mathrm{Pd}$ nanosheets' solution color, corresponding to increase the reaction time. It demonstrated that the reaction rate of reducing agents using $\mathrm{CTAB}$ and $\mathrm{W}(\mathrm{CO})_{6}$ significantly affects particle size control of synthetic $\mathrm{Pd}$ nanosheets in the mixture solution.

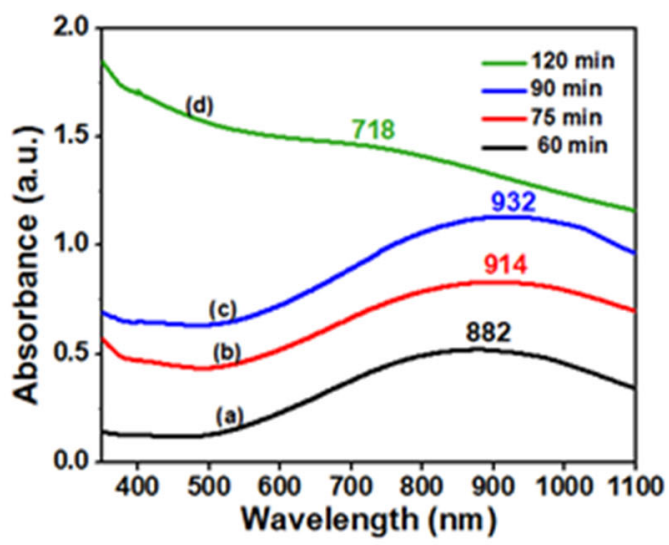

Fig. 1: UV-vis spectra of Pd nanosheets with various reaction times of (A) Using CO gas directly as a reducing agent (a) $60 \mathrm{~min}$, (b) $90 \mathrm{~min}$, and (c) $120 \mathrm{~min}$; and (B) Using W(CO)6 as a reducing agent (a) $60 \mathrm{~min}$, (b) $75 \mathrm{~min}$, (c) $90 \mathrm{~min}$, and (d) $120 \mathrm{~min}$, respectively

The XRD pattern of palladium nanosheets is shown in Figure 2. Accordingly, the characteristic peaks for $\mathrm{Pd}$ nanosheets appearing at $2 \theta=40.9^{\circ}, 46.9^{\circ}$, and $68^{\circ}$ are respectively represented the $\{111\},\{200\}$, and $\{220\}$ Bragg reflection. The XRD pattern is also compared with the Joint Committee on Powder
Diffraction Standards (JCPDS) (No. 05-0681), which is confirmed the formation of palladium nanosheets with cubic (fcc) crystal structure. This is consistent with the previously reported results (Bankar et al., 2010, Yang et al., 2010, Siddiqi et al., 2016).

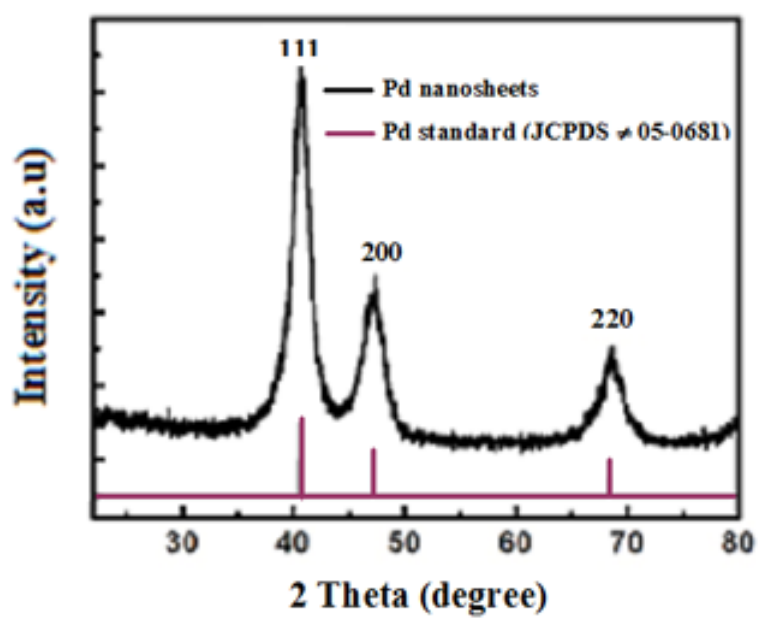

Fig. 2: XRD pattern of $\mathrm{Pd}$ nanosheets at $80^{\circ} \mathrm{C}$ for 90 min using $\mathrm{W}(\mathrm{CO})_{6}$ as a reducing agent 
Transmission electron microscopy (TEM) was used to observe the morphology and the characterization of $\mathrm{Pd}$ nanosheets synthesized. Figure 3 shows representative TEM images of Pd nanosheets sample. From TEM images in Figure 3, most of the nanocrystals have shape like as a hexagon profile. It is clear that each hexagonal nanosheet consists of six regular triangles. The average particle size of the $\mathrm{Pd}$ nanosheets is measured $\sim 20-25 \mathrm{~nm}$ (using $\mathrm{CO}$ gas directly) (Figure 3(a)) and around $15-20 \mathrm{~nm}$ (using $\left.\mathrm{W}(\mathrm{CO})_{6}\right)-($ Figure $3(\mathrm{~b}-\mathrm{e})$ ), respectively.
There is no agglomeration of nanosheets may be due to the presence of PVP as a capping agent. As shown in Figure 3, the particle size of Pd nanosheets using $\mathrm{W}(\mathrm{CO})_{6}$ as a reducing agent is round $15-20 \mathrm{~nm}$ smaller than as compared to Pd nanosheets using $\mathrm{CO}$ gas directly being $\sim 20-25 \mathrm{~nm}$. Moreover, the shape of $\mathrm{Pd}$ hexagonal nanosheets obtained in Figure $3(\mathrm{~d})$ with reaction time at $90 \mathrm{~min}$ and $80^{\circ} \mathrm{C}$ using $\mathrm{W}(\mathrm{CO})_{6}$ as a reducing agent is clearer and more uniform than that of other samples for comparisons (Figure 3).

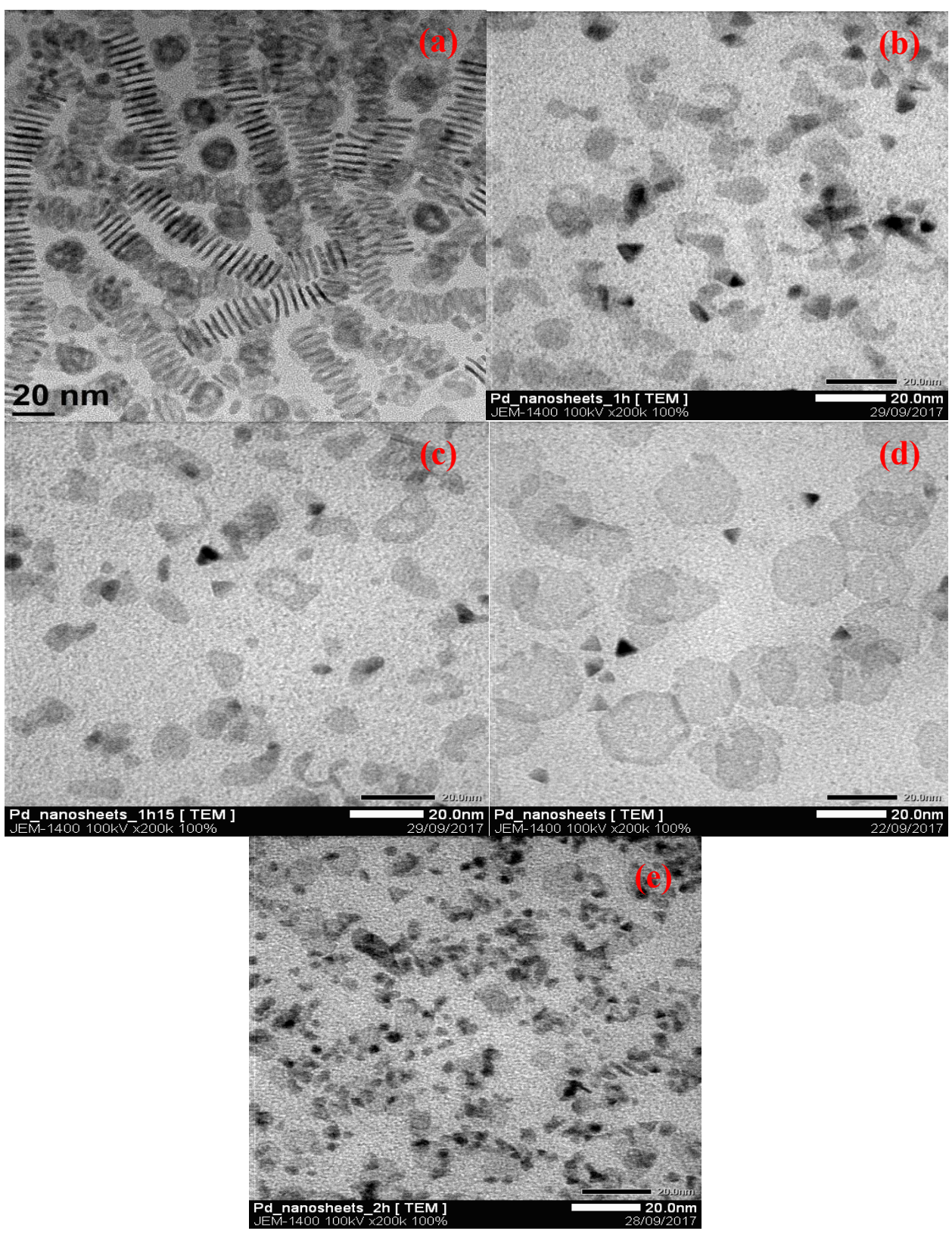

Fig. 3: TEM images of Pd nanosheets (a) Using $\mathrm{CO}$ gas directly at $80^{\circ} \mathrm{C}$ for $90 \mathrm{~min}$ and (b-e) Using $\mathrm{W}(\mathrm{CO})_{6}$ at $80^{\circ} \mathrm{C}$ with various reaction times of (b) $60 \mathrm{~min}$, (c) $75 \mathrm{~min}$, (d) $90 \mathrm{~min}$, and (e) $120 \mathrm{~min}$, respectively 
Therefore, the optimal sample with reaction condition at $80^{\circ} \mathrm{C}$ for 90 min using $\mathrm{W}(\mathrm{CO})_{6}$ as a reducing agent will be chosen to synthesize $\mathrm{Pd}$ nanosheets for the following investigations.

\section{CONCLUSIONS}

In this study, a simple and facile approach to the synthesis of Pd nanosheets with uniform shape and small particle size has been successfully modified the synthetic method of Huang et al. (2010). The used citric acid, CTAB and $\mathrm{CO}$ gas or $\mathrm{W}(\mathrm{CO})_{6}$ were found to play important roles in facilitating the formation of such nanosheets. It proves to be an ecofriendly, simple and non-toxic approach when using $\mathrm{W}(\mathrm{CO})_{6}$ as a reducing agent for the Pd nanosheets' synthesis. It indicated that synthesized $\mathrm{Pd}$ nanosheets have uniform, average edge length $\sim 20$ $\mathrm{nm}$. The Pd nanosheets with different average edge lengths as well as various reducing agents and reaction times show the tunable LSPR properties in the NIR region. Therefore, it could be significantly interesting in the field of plasmon-enhanced catalysis.

\section{ACKNOWLEDGMENT}

This research is funded by Vietnam National Foundation for Science and Technology Development (NAFOSTED) under grant number 103.99-2016.04.

\section{REFERENCES}

Astruc, D., 2007. Palladium Nanoparticles as Efficient Green Homogeneous and Heterogeneous Carbon-Carbon Coupling Precatalysts: A Unifying View. Inorganic Chemistry, 46(6): 1884-1894.

Bankar, A., Joshi, B., Kumar, A. R. and Zinjarde, S., 2010. Banana peel extract mediated novel route for the synthesis of palladium nanoparticles. Materials Letters, 64(18): 1951-1953.

Berhault, G., Bisson, L., Thomazeau, C., Verdon, C. et al., 2007. Preparation of nanostructured Pd particles using a seeding synthesis approach-Application to the selective hydrogenation of buta-1,3-diene. Applied Catalysis A: General, 327(1): 32-43.

Bouarab, S., Demangeat, C., Mokrani, A. and Dreyssé, H., 1990. Onset of magnetism in palladium slabs. Physics Letters A, 151(1): 103-105.

Duan, H., Yan, N., Yu, R., Chang, C.-R. et al., 2014. Ultrathin rhodium nanosheets. Nature Communications, 5(1): 1-8.

Franzén, R., 2000. The Suzuki, the Heck, and the Stille reaction - three versatile methods for the introduction of new CC bonds on solid support. Canadian Journal of Chemistry, 78(7): 957-962.

Hong, J. W., Kim, Y., Wi, D. H., Lee, S. et al., 2016. Ultrathin Free-Standing Ternary-Alloy Nanosheets.
Angewandte Chemie International Edition, 128(8): 2803-2808.

Huang, X., Tang, S., Mu, X., Dai, Y. et al., 2010. Freestanding palladium nanosheets with plasmonic and catalytic properties. Nature Nanotechnology, 6(2011): 28-32.

Huang, X., Li, S., Huang, Y., Wu, S. et al., 2011. Synthesis of hexagonal close-packed gold nanostructures. Nature Communications, 2(1): 2921 2916.

Huang, X., Zeng, Z. and Zhang, H., 2013. Metal dichalcogenide nanosheets: preparation, properties and applications. Chemical Society Reviews, 42(5): 1934-1946.

Hübert, T., Boon-Brett, L., Black, G. and Banach, U., 2011. Hydrogen sensors - A review. Sensors and Actuators B: Chemical, 157(2): 329-352.

Kishore, S., Nelson, J. A., Adair, J.H. and Eklund, P. C., 2005. Hydrogen Storage in Spherical and Platelet Palladium Nanoparticles. Journal of Alloys and Compounds, 389(1): 234-242.

Kooij, E. S., W. Ahmed, H. J. W. Zandvliet and B. Poelsema, 2011. Localized Plasmons in Noble Metal Nanospheroids. The Journal of Physical Chemistry C, 115(21): 10321-10332.Langhammer, C., I. Zorić, B. Kasemo and B. M. Clemens, 2007. Hydrogen Storage in Pd Nanodisks Characterized with a Novel Nanoplasmonic Sensing Scheme. Nano Letters, 7(100): 3122-3127.

Li, Y., Hong, X. M. F. A. U. C., Collard, D. M. F. A. U. E.S. and El-Sayed, M. A., 2000. Suzuki cross-coupling reactions catalyzed by palladium nanoparticles in aqueous solution. Organic Letters, 2(15): 2385-2388.

Li, Y., Lu, G., Wu, X. and Shi, G., 2006.

Electrochemical Fabrication of Two-Dimensional Palladium Nanostructures as Substrates for Surface Enhanced Raman Scattering. The Journal of Physical Chemistry B, 110(48): 24585-24592.

Li, Y., Yan, Y., Li, Y., Zhang, H. et al., 2015. Sizecontrolled synthesis of Pd nanosheets for tunable plasmonic properties. CrystEngComm, 17(8): 18331838.Perez-Alonso, F. J., McCarthy Dn Fau Nierhoff, A., Nierhoff A Fau - HernandezFernandez, P., Hernandez-Fernandez P Fau - Strebel, C. et al., 2012. The effect of size on the oxygen electroreduction activity of mass-selected platinum nanoparticles. Angewandte Chemie International Edition, 51(19): 4641-4643.

Mendoza, D., Morales, F., Escudero, R., and Walter, J., 1999. Magnetization studies in quasi twodimensional palladium nanoparticles encapsulated in a graphite host. Journal of Physics Condensed Matter, 11(28): L317-L322.

Rao, C. N. R. M., A.; Cheetham, A. K, Eds., 2004. The Chemistry of Nanomaterials: Synthesis, properties and applications. Wiley-VCH Verlag GmbH \& Co. KGaA, 1: 1-11.

Redjala, T., Remita, H., Apostolescu, G., Mostafavi, M., Thomazeau, C., and Uzio, D., 2006. Bimetallic Au- 
Pd and Ag-Pd Clusters Synthesised by $\$ \backslash$ gamma $\$$ or Electron Beam Radiolysis and Study of the Reactivity/Structure Relationships in the Selective Hydrogenation of Buta-1,3-Diene. Oil Gas Science and Technology- Reviews IFP, 61(6): 789-797.

Reetz, M. T. and Westermann, E., 2000. Phosphane-Free Palladium-Catalyzed Coupling Reactions: The Decisive Role of Pd Nanoparticles. Angewandte Chemie International Edition, 39(1): 165-168.

Roucoux, A., Schulz, J., and Patin, H., 2002. Reduced transition metal colloids: a novel family of reusable catalysts? Chemical Reviews, 102(10): 3757-3778

Saleem, F., Zhang, Z., Xu, B., Xu, X. et al., 2013. Ultrathin $\mathrm{Pt}-\mathrm{Cu}$ Nanosheets and Nanocones. Journal of the American Chemical Society, 135(49): 1830418307.

Siddiqi, K. S. and Husen, A., 2016. Green Synthesis, Characterization and Uses of Palladium/Platinum Nanoparticles. Nanoscale Research Letters, 11(1): 482-491.

Son, S. U., Jang Y., Park, J., et al., 2004. Designed synthesis of atom-economical $\mathrm{pd} / \mathrm{ni}$ bimetallic nanoparticle-based catalysts for sonogashira coupling reactions. Journal of the American Chemical Society, 126(16): 5026-5027.

Sun, S., Murray, C. B., Weller, D., Folks, L., and Moser, A., 2000. Monodisperse FePt Nanoparticles and Ferromagnetic FePt Nanocrystal Superlattices. Science, 287(5460): 1989-1992.
Suzuki, M., Suzuki, I. S., and Walter, J., 2000. Magnetic properties of palladium-graphite multilayers. Physical Review B, 62(21): 14171-14180.

Tobiška, P., Hugon, O., Trouillet, A., and Gagnaire, H., 2001. An integrated optic hydrogen sensor based on SPR on palladium. Sensors and Actuator B: Chemical, 74(1-3): 168-172.

Xiong, Y., Wiley, B., Chen, J., Li, Z. Y., Yin, Y., and Xia, Y., 2005. Corrosion-based synthesis of singlecrystal Pd nanoboxes and nanocages and their surface plasmon properties. Angewandte Chemie International Edition, 44(48): 7913-7917.

Xiong, Y., McLellan, J. M., Chen, J., Yin, Y., Li, Z. Y., and Xia, Y., 2005. Kinetically controlled synthesis of triangular and hexagonal nanoplates of palladium and their SPR/SERS properties. Journal of the American Chemical Society, 127(48): 17118-17127.

Xu, C. W., Wang, H., Shen, P. K. and Jiang, S. P., 2007. Highly Ordered Pd Nanowire Arrays as Effective Electrocatalysts for Ethanol Oxidation in Direct Alcohol Fuel Cells. Advanced Materials, 19(23): 42564259.

Yang, X., Li, Q., Wang, H., Huang, J. et al., 2010. Green synthesis of palladium nanoparticles using broth of Cinnamomum camphora leaf. Journal of Nanoparticle Research, 12(5): 1589-1598.

Yin, X., Liu, X., Pan, Y.T., Walsh, K. A. et al., 2014. Hanoi Tower-like Multilayered Ultrathin Palladium Nanosheets. Nano Letters, 14(12): 7188-7194. 